\title{
Particle size control during ultrasonic cooling crystallization of paracetamol
}

Bjorn Gielen $^{\dagger}$, Thomas Claes ${ }^{\dagger}$, Jonas Janssens ${ }^{\ddagger}$, Jeroen Jordens ${ }^{\dagger}$, Leen C.J. Thomassen ${ }^{\dagger \dagger}$, Tom Van Gerven ${ }^{\dagger}$, Leen Braeken ${ }^{\dagger *}$

${ }^{\dagger}$ KU Leuven, Department of Chemical Engineering, Celestijnenlaan 200 F, box 2424, 3001 Leuven, BELGIUM

${ }^{\ddagger}$ KU Leuven, Faculty of Engineering Science, Lab4U, Agoralaan building B box 8, 3590

Diepenbeek, BELGIUM

\begin{abstract}
This study investigated the effect of ultrasound on the crystal size during cooling crystallization of paracetamol. Sonication was enabled in three distinct stages to define the operating guidelines for crystal size control. In addition, it was identified whether size reduction results from a higher amount of nuclei upon primary nucleation or from enhanced secondary nucleation. The results show that tuning of the ultrasonic power density and exposure time after nucleation results in a crystal size between 70-140 $\mu \mathrm{m}$. In contrary, the use of ultrasound before nucleation does not affect the size, indicating enhanced secondary nucleation as the main mechanism. Finally, sonication after complete desupersaturation reduces the crystal size by about $30 \mu \mathrm{m}$, but causes surface erosion.
\end{abstract}

*Leen Braeken

Agoralaan building B box 8

3590 Diepenbeek, Belgium

Tel: +3211268129

Email: leen.braeken@kuleuven.be

www.khlim.be/expertise/lab4u-bio-chemische-procestechnologie 


\section{Introduction}

Crystallization is an important separation technique in the pharmaceutical industry during the manufacturing of active pharmaceutical ingredients (APIs). ${ }^{1,2}$ The characteristics of these compounds such as purity, size distribution, polymorphic form, etc. should be controlled in a reproducible way since these determine the drugs' effectiveness in the human body and shelf life. $^{3-17}$

The key to a successful crystallization is to control the stochastic nucleation event and initiate the process in a reproducible way. Therefore, an approach with the addition of seed crystals is often applied in industry to obtain a predictable process, produce the desired crystal form and obtain a narrow crystal size distribution in a certain range of interest. ${ }^{3,71,18}$ Additionally, the use of ultrasound as an alternative seeding source has been suggested, and is based on its ability to induce nucleation at low supersaturation, shorten the induction time and decrease the metastable zone width (MSZW). Although the origin of these effects remains uncertain, many believe that acoustic cavitation, i.e. cyclic formation and implosion of micron-sized bubbles, is involved in this process. ${ }^{20,21}$ Furthermore, a reduced particle size, change in particle shape, higher yield and more uniform distribution can be obtained during sonocrystallization. ${ }^{2,6,22-27}$ Similarly, other work on the application of ultrasound during crystallization indicated the possibility to 'tailor' the final crystal size and shape by adequate settings of the sonication parameters. In general, an inverse dependency of the particle size to the sonication time and/or ultrasonic power is reported for various organic compounds. ${ }^{18,22,28-33}$ For example, Hatkar et al. showed that an increase in the ultrasonic irradiation time or power during cooling crystallization of sodium acetate decreased the particle diameter to a range of 8-12 $\mu \mathrm{m} .{ }^{18}$ In addition, Su et al. were able to tune the particle size of phenacetin within a range of $15-45 \mu \mathrm{m}$ depending on the ultrasonic intensity and duration. Prolonged exposure to a higher intensity yielded the smallest crystals, and was attributed by the authors to a greater number of nuclei in comparison to the silent process that produced particles of $87.5 \mu \mathrm{m} .{ }^{11}$ Similarly, Bhangu et al. demonstrated that a change in ultrasonic frequency and power was able to change the median crystal size of paracetamol in a range of $10-50 \mu \mathrm{m}$. Additional work on sonocrystallization of paracetamol is published by other groups. . $^{34,27,35}$

Although the previous studies showed that the crystal size can be reduced by increasing the ultrasonic exposure time or power, the exact mechanism remains ambiguous. Some claim that ultrasound predominantly generates a larger number of primary nuclei that eventually grow to multiple smaller crystals ${ }^{8,36,37}$, while others link the reduced particle size to disaggregation of early formed particles. ${ }^{14,38,39}$ The latter studies therefore reject the assumption that sonication produces a larger amount of primary nucleation. In agreement with this statement, a study on the sonicated nucleation of lysosome crystals reported that the ultrasonic field can only increase the nucleus number by mechanical breakage of protein crystals that are already present in the solution. ${ }^{40}$ Overall, it remains unclear whether the ultrasound-induced particle reduction is caused by a larger initial number of (primary) nuclei or additional formation of (secondary) nuclei, induced by breakage and disaggregation of pre-existing particles. ${ }^{16,17}$ 
Furthermore, previous work applied ultrasound in fixed time intervals without taking into account whether the solution completely desupersaturated in this time frame. Since sonication in the presence or absence of supersaturation can affect the existing crystals in a different way, it should be studied as a separate process.

Therefore, the present work divides the crystallization process into distinct stages, as shown in Figure 1, and investigates the effect of ultrasound herein. ${ }^{14,41,42}$ The demarcation between the first and second stage is based on the detection of nucleation in the solution. The crystals detected upon nucleation are referred to as primary crystals, though it is acknowledged that these might have been formed after fragmentation from a single parent crystal. ${ }^{43}$ Additional formation of crystals after the initial nuclei detection is considered as secondary nucleation. Therefore, a comparison of the PSD between samples with application of ultrasound in either stage 1 or 2 is able to demonstrate the effect of sonication on primary and secondary nucleation. In addition, this allowed to identify the dominant mechanism for particle size reduction by ultrasound. Furthermore, the effect of ultrasound before and after complete desupersaturation was investigated by a shape and size analysis of crystals that were sonicated in either stage 2 or 3 . In the end, this study provides more insight into the mechanism of sonocrystallization and presents a process window to produce undamaged crystals with a controllable size. 


\section{Materials and methods}

\subsection{Experimental setups}

The Supporting Information (Section 1.1) provides a detailed overview of the batch and recirculation setup that were used in this study.

\subsection{Preparation of supersaturated solution}

The procedure for preparation of a supersaturated $20 \mathrm{~g} \cdot \mathrm{kg}^{-1}$ paracetamol solution and the corresponding solubility data, is described in the Supporting Information (Section 1.2).

\subsection{General experimental procedure}

Ultrasound is applied in three distinct stages during an isothermal crystallization process, of which the supersaturation level progresses according to Figure 1. The first stage is confined by the first detection of crystals in the solution. In these set of experiments, sonication was enabled at a constant power till the first crystals were detected by the naked eye. The time span between start of sonication and detection of nucleation was recorded, and afterwards the solution was stirred for 2 hours to guarantee complete desupersaturation.

After the formation of the first nuclei, crystal growth and secondary nucleation occur until the supersaturation is completely depleted. Activation of ultrasound subsequent to the detection of nuclei, is defined as the second stage. During these experiments, the nucleation event was either initiated by ultrasound, or was allowed to occur spontaneously after a sufficient waiting time without application of ultrasound. In both cases, only the sonication time after nucleation was monitored and various time settings were tested using a constant ultrasonic power. Similarly as the previous tests, the solution was stirred for 2 hours after sonication was stopped, followed by isolation of the crystals.

Application of ultrasound in the third stage was evaluated to study whether sonication can be used as an after-treatment to control the particle size. At first, the crystallization was completed in the absence of ultrasound by stirring the solution for about 12 hours after detection of spontaneous nucleation. Next, a sample was taken and after filtration and drying, the particle size distribution was determined. Subsequently, the solution was treated with ultrasound and the final crystal size was determined again.

A more detailed procedure of the experiments conditions, the results and the corresponding analytical protocols are available in the Supporting Information (Section $1.3 \&$ Section 2.2). 


\section{Results and discussion}

\subsection{Effect of ultrasound in stage 1}

This set of experiments was performed in the recirculation setup and ultrasound was applied until nucleation was observed by visual detection in the $600 \mathrm{~mL}$ tank. The time till the detection of nucleation, shown in Figure 2, exhibits a clear variation due to the stochastic nature of the crystallization process.

Additionally, these results show that an ultrasonic power of more than $10 \mathrm{~W}$ reduces the nucleation time and improves the reproducibility. The latter can be observed by a reduction of the standard deviation in Figure 2. Sonication at elevated power thus reduces the stochasticity of the nucleation event, converting crystallization into a quasi-deterministic process. This reduction in nucleation time by application of ultrasound was observed before by other groups. ${ }^{2,26,44}$ In general, it is believed that the improvement is related to the presence of cavitation bubbles and the accompanying effects such as shockwaves, turbulences and microstreaming. ${ }^{20,21}$ As an increase in ultrasonic power promotes cavitation phenomena, this will result in further enhancement of nucleation. The lack of improvement below $10 \mathrm{~W}$ in our experiments might be attributed to the existence of a power threshold, as proposed by Miyasaka et al. According to their study, a specific amount of ultrasonic energy is needed to promote nucleation and this threshold depends on the supersaturation of the solution. ${ }^{8,36,37}$ In addition, they showed an inhibition region at low input energy ( $<60 \mathrm{~J}$ at $\mathrm{S}=1.48$ ) in which the nucleation time increased by application of ultrasound. This was attributed to ultrasoundinduced disruption of sub-nuclei or molecular clusters. Although this negative effect on the induction time was not observed in our study, it is possible that we were operating at the transition of the inhibition into the promotional region in the tests where a power of $10 \mathrm{~W}$ was used.

Since a change in nucleation behaviour can affect the final crystal properties, the particle size distribution after complete desupersaturation was determined by laser diffraction. Figure 3 shows the volume and number based median particle size of these distributions, plotted on a linear axis. The complete volume based PSD plots exhibit a unimodal distribution with a comparable span and are shown in the Supporting Information (Section 2.1).

These results indicate that application of ultrasound in the first stage does not significantly alter the final particle size. This is in contrast with most publications that report a strong decrease in particle size at elevated ultrasonic power or prolonged exposure. However, most studies apply a fixed sonication time and could therefore induce nucleation within this time frame. As a result, the primary formed crystals are subjected to cavitation effects that might cause fragmentation and disaggregation of crystals. This effect was clearly demonstrated by Chow et al. while studying the effect of ultrasound on the nucleation of ice in sucrose solutions. ${ }^{16,17}$ This demonstrated that fragmentation of existing ice dendrites already occurs after an exposure time of less than $2 \mathrm{~s}$. Furthermore, the authors found that the fragmented ice crystals acted as new nuclei in the solution and continued to grow. Later on, this sonofragmentation phenomenon was also observed for organic compounds. Consequently, it was suggested that the final product size can be controlled by varying the ultrasonic energy 
input after addition of seed material. ${ }^{5,45}$ Similarly, Wagterveld et al. reported that disaggregation of clustered nuclei immediately after nucleation is the main cause for improved nucleation kinetics. ${ }^{14}$ Hence, it is important to acknowledge that ultrasound has a significant effect on the size of crystals present in the solution, even those formed in an early state of crystallization.

In the present study, great effort was made to disable sonication after primary nucleation has occurred. However, taken into account that an additional growth time is needed to develop the nuclei to a detectable size, the primary generated submicron crystals were also briefly exposed to the sound field in our experiments. ${ }^{43,46}$ Despite this shortcoming, we did not observe any reduction in the particle size by application of ultrasound during the initial stage of crystallization. Therefore, these results strongly suggest that the frequently reported particle size reduction by application of ultrasound during crystallization is predominantly caused by rapid formation of additional nuclei after the first formation of crystals due to prolonged sonication after nucleation. Hence, ultrasound does not increase the initial seed mass (primary nucleation), but mainly promotes the subsequent formation of nuclei, defined as secondary nucleation. Although most authors report that secondary nucleation is caused by fragmentation and disaggregation, additional nuclei formation solely induced by cavitation without disruption of other crystals is still plausible. Most likely, both effects will boost the formation of additional particles immediately after the first occurrence of crystals. The strong enhancement of secondary nucleation by ultrasound can be attributed to the intensification of the cavitation phenomena in the presence of solids. After all, the system becomes heterogeneous resulting in a lower cavitation threshold. ${ }^{47}$

The above findings are further supported in literature comparing conventional and ultrasound assisted cooling crystallization. ${ }^{14,38-40}$ Therefore, our results provide evidence to support these claims.

\subsection{Effect of ultrasound in stage 2}

\subsubsection{Analysis in recirculation setup}

In this part, it is evaluated whether exposure to ultrasound after nucleation influences the final particle size. At first, the effect of sonication after both spontaneous and ultrasonic-induced nucleation was studied using the recirculation configuration. Later on, the batch setup was used to investigate the influence of the slurry volume and ultrasonic intensity during sonication in the second stage. In the latter experiments, nucleation was always induced by ultrasound.

Figure 4 shows the evolution of the median particle size for different ultrasonic treatment times, starting from a solution in which nucleation occurred spontaneously or was induced by ultrasound. Firstly, it is observed that the final particle size is independent of the way nucleation was introduced. Similar particle sizes were produced if an equal sonication time is used after spontaneous or ultrasound-induced nucleation, taken statistical error and some 
deviation on the detection of nucleation into account. In general, the trend confirms the earlier statements that ultrasound does not create a higher initial seed mass upon nucleation. Secondly, these results show that the final crystal size can be reduced if sonication is maintained after nucleation. In agreement with other publications, a longer exposure to ultrasound yields a smaller crystal size. As discussed previously, this is attributed to fragmentation, disaggregation and nucleation induced by the presence of cavitation bubbles. ${ }^{6,11,31,48-50}$

The particle size seems to reach a minimum at $10 \mathrm{~min}$, after which the size tends to increase again. It is plausible this is caused by statistical fluctuations. Repetitions and experiments with a longer ultrasonic exposure time are needed to clarify this observation. Additionally, it is possible that the solution has reached the solubility level after an exposure to ultrasound with a power of $40 \mathrm{~W}$ for more than $10 \mathrm{~min}$. At this point, the driving force for crystallization diminishes, inhibiting further nucleation and growth. However, as ultrasound is still switched on, two effects remain active. On the one hand, Ostwald ripening, induced by the heat effect of ultrasound and the size-dependant solubility, will result in the formation of larger crystals. ${ }^{14,51,52}$ On the other hand, sonofragmentation can still proceed, reducing the overall crystal size by introducing small fragments in the solution. ${ }^{53}$ Competition between both effects could thus also cause the particle size to fluctuate.

Additionally, Figure 4 shows the effect of acoustic power during the sonication period after nucleation. It is clear that the decline of the particle size is reduced if a lower acoustic power is applied. This can be attributed to a decrease in the power dissipation in the system which in turn diminishes the cavitation effects. ${ }^{31}$ In turn, this can again be correlated to a decrease in secondary nucleation and disaggregation events. Consequently, less surface area becomes available for deposition of crystalline material and the desupersaturation progresses more slowly in comparison to an elevated ultrasonic power. ${ }^{14,54}$

In the end, these results show that the particle size can be tuned by both the ultrasonic power and exposure time if sonication is applied after nucleation. A lower ultrasonic power can be more beneficial if a very accurate intermediate particle size is desired. Hence, application of a reduced power input will only cause a limited change in size if the exposure time is inaccurately controlled. However, it should be considered that a longer processing time is needed to gain accurate control over the particle size. In contrast, when both a minimal particle size and short processing time are required, higher power levels are more suitable. 


\section{$\underline{\text { 3.2.2 Analysis in batch setup }}$}

The approach of a variable ultrasonic treatment time after nucleation to reduce the particle size was also evaluated in a batch setup while using the same ultrasonic actuator as the recirculation setup. This allowed to study the effect of slurry volume and ultrasonic power on the final particle size. Figure 5 (a) and (b) show that both a volume of $250 \mathrm{~mL}$ and $2000 \mathrm{~mL}$ exhibit a decline in particle size by increasing the sonication period, similar as discussed before for the recirculation setup. In addition, elevated power exhibits a faster drop in the particle size due to enhanced cavitational effects that promote nucleation and fragmentation or disaggregation. A decrease in volume yields the smallest crystals and requires a shorter exposure time to ultrasound to affect the crystal size. This effect can be attributed to a change in the power density (W.L $\mathrm{L}^{-1}$ ), as was also discussed by Li et al. A lower power dissipation reduces the ultrasonic effects and will diminish the particle reduction. ${ }^{31}$ In terms of scale-up, these results indicate that the ultrasonic power has to increase when a larger reaction volume has to be sonicated. In a batch configuration this will require ultrasonic actuators operating at a higher intensity, or the use of multiple sonicators. ${ }^{55-57}$ However, most researchers agree that placement of ultrasound in a flow or recirculation systems provides a more elegant scale-up solution as the ultrasonic energy can be focused and confined in a small volume, boosting the cavitation intensity. ${ }^{56,58-61}$

Since only 1 min additional treatment with ultrasound after nucleation can already significantly change the particle size, it is reasonable that some publications assume that improved primary nucleation caused the reduction in particle size, especially if it is considered that this effect is even more pronounced when a high power density (W.L ${ }^{-1}$ ) is used. For example, the $D_{50}$ is reduced by almost 4 times during the tests with $250 \mathrm{~mL}$ by application of $50 \mathrm{~W}$ for only $1 \mathrm{~min}$ after nucleation, indicating the strong influence of sonication in the presence of crystals. A delay in the observation of nuclei during sonication might already cause a significant change in the particle size. As indicated earlier, the method employed in this study is also not impeccable and most likely primary nucleation has already ended before the ultrasound is disabled. Nonetheless, it is clear that the most significant effect of ultrasound on the particle size arises during the second stage, in the presence of the first nuclei.

Finally, the crystal morphology in the batch and recirculation setup was assessed by SEM imaging. Figure 6 shows the crystals that were obtained by conventional seeding experiments and by an ultrasonic treatment during the second stage. Also, the seed material that was used in the former tests is presented.

It is clear that ultrasound assisted crystallization yields a similar morphology as those obtained by a conventional seeding approach. Although Bhangu et al. recently showed that ultrasound can produce the unstable orthorhombic polymorph (form II) of paracetamol, only the monoclinic form, confirmed by XRD spectra, was obtained in our study. ${ }^{62}$ However, as we only imaged the crystals after an additional stirring time of more than 2 hours in silent conditions, it is possible that all crystals converted to the more stable monoclinic (form I). In 
addition, a relatively low supersaturation was maintained in the present study, favouring the formation of the thermodynamically stable forms. ${ }^{62,63}$

Close examination of the crystals revealed no distinct damage caused by cavitation as smooth surfaces were obtained while using a sonication period up to 10-20 min. Longer treatments only resulted in very limited defects on the crystal edges. These damaging effects of ultrasound were investigated by Zeiger et al. who identified particle-shockwave interactions as the main contributor to ultrasound induced fragmentation and breakage. ${ }^{5,64}$ Later on, Wagterveld et al. also claimed that microjet formation, resulting from asymmetrical collapse of cavitation bubbles, could play a role in this process. ${ }^{65,66}$ The absence of extensive crystal damage in our experiments can be attributed to deposition of crystalline material subsequent to the occurrence of crystal defects. This 'crystal healing' can only proceed as long as the solution has not yet reached its solubility level. Beyond the solubility level, no additional crystalline material will form from the solution to restore the crystal shape. Hence, it should be noticed that the length of the sonication period in the second stage cannot be chosen independently if undamaged crystals are desired. The available ultrasonic treatment time in this stage is determined by the rate of desupersaturation, which in turn depends on the ultrasonic power. Application of a high power density only allows for a limited process window to tune the particle size due to the fast depletion of the supersaturation. ${ }^{14,67,68}$

\subsection{Effect of ultrasound in stage 3}

In the final set of experiments, ultrasound was applied after complete desupersaturation of the solution, specified as stage 3. This approach was tested in the batch setup, using an additional exposure time of $30 \mathrm{~min}$ and a power of $10 \mathrm{~W}$. The PSD before and after sonication are displayed in Figure 7 (a) and (b) using a volume and a number distribution, respectively.

The volume based median particle size only reduces by $30 \mu \mathrm{m}$ after $10 \mathrm{~min}$ of sonication. This effect is therefore much smaller compared to sonication in the second stage where an equivalent exposure time caused a drop of almost $300 \mu \mathrm{m}$. In contrast, the number size distribution converts from bimodal to unimodal and indicates a clear conversion of large particles into small fragments. On the one hand, these fragments originate from ultrasoundinduced crystal breakage, as was discussed before. On the other hand, disaggregation will also contribute to the reduction in particle size. In general, it is clear that predominantly small fragments will be generated by an after-treatment with ultrasound, proven by the limited change in the volume-based median particle size. Similarly as in stage 2, Ostwald ripening can occur, resulting in the dissolution of small fragments, followed by redisposition on existing crystals. ${ }^{14,51}$ Although this effect might restore some of the crystal defects, particle breakage will dominate throughout the third stage due to the absence of supersaturation.

The effect on particle morphology is shown by SEM images, displayed in Figure 8. These clearly indicate that pit erosion, edge defects and disaggregation arise due to the ultrasonic treatment. On the contrary, other studies showed that prolonged sonication of several hours can yield smooth crystals. Most likely, the surface and edge defects are eliminated by 
continuous abrasion and fracture of the crystals. In some cases, this even results in spherical particles next to a large amount of fines. ${ }^{69-72}$ In our experiments, crystal deformations were not present when ultrasound was applied in stage 2, which provides a more suitable approach to control the final particle size.

\subsection{General mechanism for particle size control}

Table 1, compiled from observations of this and previous studies, presents an overview of the different stages in which ultrasound can be applied during a crystallization process. For each of these, it is indicated which main effect is caused by ultrasound and which fundamental mechanisms are induced during sonication. This table also specifies how the ultrasonic power and treatment time can be altered within a particular stage to control the nucleation time or particle size.

In the first stage, the ultrasonic power completely controls the nucleation time and the stochasticity of the crystallization process. Both are reduced by application of a higher power dissipation that boosts the cavitation effects. The ultrasonic time cannot be adjusted independently in this stage as it depends on the ultrasonic power. Hence, a higher energy dissipation will reduce the time till nucleation. Control over the particle size without introducing crystal defects is possible by sonication in the second stage. If sonication is disabled before complete desupersaturation of the solution, smooth crystal surfaces are obtained with a minimum number of defects. Similarly as in stage 1, the ultrasonic power confines the total available exposure time that results in the smallest crystals. However, application of a shorter sonication time in the second stage is possible, and will yield intermediate sizes, allowing to tune the final PSD. The overall reduction in particle size in the second stage is attributed to enhanced secondary nucleation. In the final stage, both the exposure time and the power of the sound field can be controlled to influence the particle size. Due to direct interactions with cavitation shockwaves, the crystals will fracture, yielding small fragments and rough, damaged crystal surfaces. 
Table 1: Overview of the predominant effect of ultrasound in the three previously defined stages. The mechanisms that trigger these effects and the controllable parameters in each of the stages are also indicated.

\begin{tabular}{|c|c|c|c|}
\hline $\begin{array}{l}\text { Sonication } \\
\text { applied: }\end{array}$ & $\begin{array}{c}\text { Stage 1 } \\
\text { Before } \\
\text { prim. nucleation }\end{array}$ & $\begin{array}{c}\text { Stage 2 } \\
\text { After } \\
\text { prim. nucleation }\end{array}$ & $\begin{array}{c}\text { Stage 3 } \\
\text { After } \\
\text { desupersaturation }\end{array}$ \\
\hline $\begin{array}{l}\text { Predominant } \\
\text { effect on: }\end{array}$ & Nucleation time & $\begin{array}{c}\text { PSD } \\
\text { Undamaged crystals }\end{array}$ & $\begin{array}{c}\text { PSD } \\
\text { Damaged crystals }\end{array}$ \\
\hline Mechanisms: & Unknown & $\begin{array}{l}\text { - Secondary nucleation } \\
\text { (fragmentation, } \\
\text { disaggregation) } \\
\text { - Crystal 'healing' } \\
\text { - Ostwald ripening }\end{array}$ & $\begin{array}{l}\text { - Fragmentation } \\
\text { - Ostwald ripening }\end{array}$ \\
\hline $\begin{array}{l}\text { Controllable } \\
\text { parameters: }\end{array}$ & $\begin{array}{c}P_{U S} \uparrow: t_{\text {nucl }} \downarrow \\
P_{U S} \uparrow: \text { stochasticity } \downarrow \\
t_{U S} \text { depends on } P_{U S}\end{array}$ & $\begin{array}{c}P_{U S} \uparrow: \mathrm{PSD} \downarrow \text { during } t_{\text {desup }} \\
P_{U S} \uparrow: t_{\text {desup }} \downarrow^{*}\end{array}$ & $\begin{array}{c}P_{U S} \uparrow: P S D \downarrow \\
t_{U S} \uparrow: P S D \downarrow\end{array}$ \\
\hline
\end{tabular}




\section{Conclusions}

This study evaluated the effect of sonication in three well defined stages during the crystallization process. When ultrasound is only provided till the onset of nucleation, it mainly reduces the induction time for nuclei formation without any significant effect on the final particle size. In contrast, when sonication is extended beyond the detection of nucleation (stage 2), a strong reduction in particle size can be obtained till the solution reaches its solubility level. Both stages are predominantly controlled by the ultrasonic power that limits the total sonication time within each phase. In order to obtain undamaged crystals with a tuneable final particle size distribution, this maximum ultrasonic treatment time should be taken into account. Application of ultrasound in the third stage after complete desupersaturation will give rise to sonofragmentation, resulting in smaller crystals that might show surface defects if a relatively short treatment time is chosen. In the end, this paper excludes the formation of more primary nuclei by ultrasound as the main effect for particle size reduction under the chosen experimental conditions. Instead, enhanced secondary nucleation, triggered by cavitation-induced nucleation and disaggregation or fragmentation of existing crystals, is identified as the most important factor for particle size reduction. This knowledge allows to tune the final particle size distribution within a predefined range by a correct setting of the ultrasonic parameters. 


\section{References}

(1) Giulietti, M.; Seckler, M. M.; Derenzo, S.; Ré, M. I.; Cekinski, E. Brazilian J. Chem. Eng. 2001, 18 (4), 423-440.

(2) Zeng, G.; Li, H.; Luo, S.; Wang, X.; Chen, J. Korean J. Chem. Eng. 2014, 31 (5), 807811.

(3) Bhoi, S.; Sarkar, D. CrystEngComm 2016, 18 (25), 4863-4874.

(4) Dalvi, S. V.; Dave, R. N. Ind. Eng. Chem. Res. 2009, 48 (16), 7581-7593.

(5) Zeiger, B. W.; Suslick, K. S. J. Am. Chem. Soc. 2011, 133 (37), 14530-14533.

(6) Iyer, S. R.; Gogate, P. R. Ultrason. Sonochem. 2017, 34, 896-903.

(7) Cote, A.; Sirota, E.; Moment, A. Am. Pharm. Rev. 2010, 13 (7).

(8) Kurotani, M.; Miyasaka, E.; Ebihara, S.; Hirasawa, I. J. Cryst. Growth 2009, 311 (9), 2714-2721.

(9) Bartos, C.; Kukovecz, Á.; Ambrus, R.; Farkas, G.; Radacsi, N.; Szabó-Révész, P. Chem. Eng. Process. Process Intensif. 2015, 87, 26-34.

(10) Narducci, O.; Jones, a. G.; Kougoulos, E. Cryst. Growth Des. 2011, 11 (5), 17421749.

(11) Su, C.-S.; Liao, C.-Y.; Jheng, W.-D. Chem. Eng. Technol. 2015, 38 (1), 181-186.

(12) Nagy, Z. K.; Braatz, R. D. Annu. Rev. Chem. Biomol. Eng 2012, 3, 55-75.

(13) Nagy, Z. K.; Fevotte, G.; Kramer, H.; Simon, L. L. Chem. Eng. Res. Des. 2013, 91 (10), 1903-1922.

(14) Wagterveld, R. M.; Miedema, H.; Witkamp, G. Cryst. Growth Des. 2012, 12 (9), 4403-4410.

(15) Vekilov, P. G. Nanoscale 2010, 2, 2346-2357.

(16) Chow, R.; Blindt, R.; Chivers, R.; Povey, M. Ultrasonics 2003, 41, 595-604.

(17) Chow, R.; Blindt, R.; Chivers, R.; Povey, M. Ultrasonics 2005, 43 (4), 227-230.

(18) Hatkar, U. N.; Gogate, P. R. Ind. Eng. Chem. Res. 2012, 51 (39), 12901-12909.

(19) Guo, Z.; Zhang, M.; Li, H.; Wang, J.; Kougoulos, E. J. Cryst. Growth 2005, 273 (3-4), 555-563.

(20) Hem, S. L. Ultrasonics 1967, 5 (4), 202-207.

(21) Wohlgemuth, K.; Kordylla, A.; Ruether, F.; Schembecker, G. Chem. Eng. Sci. 2009, 64 (19), 4155-4163.

(22) Narducci, O.; Jones, A. G. Cryst. Growth Des. 2012, 12, 1727-1735.

(23) McCausland, L. J. Production of crystalline materials by using high intensity ultrasound. US 7,244,307 B2, 2007.

(24) McCausland, L. J.; Cains, P. W. Biotechnol. Genet. Eng. Rev. 2004, 21.

(25) Mccausland, L. J.; Cains, P. W.; Martin, P. D. Fluids Solids Handl. 2001, No. July, 5661.

(26) Ruecroft, G.; Hipkiss, D.; Ly, T.; Maxted, N.; Cains, P. W. Org. Process Res. Dev. 2005, 9 (6), 923-932.

(27) Castillo-Peinado, L. D. L. S.; Dolores, M.; de Castro, L. J. Pharm. Pharmacol. 2016, $68,1249-1267$.

(28) Narducci, O.; Jones, A. G.; Kougoulos, E. Cryst. Growth Des. 2011, 11 (5), 17421749.

(29) Narducci, O.; Jones, a. G.; Kougoulos, E. Chem. Eng. Sci. 2011, 66 (6), 1069-1076.

(30) Sheikh, A. R.; Patel, S. R. J. Cryst. Growth 2014, 390, 114-119.

(31) Li, H.; Li, H.; Guo, Z.; Liu, Y. Ultrason. Sonochem. 2006, 13 (4), 359-363.

(32) Dhumal, R. S.; Biradar, S. V.; Paradkar, A. R.; York, P. Int. J. Pharm. 2009, 368 (1-2), 129-137.

(33) Abbas, A.; Srour, M.; Tang, P.; Chiou, H. Chem. Eng. ... 2007, 62, 2445-2453.

(34) Jordens, J.; Gielen, B.; Braeken, L.; Van Gerven, T. Chem. Eng. Process. 2014, 1-19. 
(35) Bučar, D. K.; Elliott, J. A.; Eddleston, M. D.; Cockcroft, J. K.; Jones, W. Angew. Chemie - Int. Ed. 2015, 54 (1), 249-253.

(36) Miyasaka, E.; Kato, Y.; Hagisawa, M.; Hirasawa, I. J. Cryst. Growth 2006, 289 (1), 324-330.

(37) Miyasaka, E.; Ebihara, S.; Hirasawa, I. J. Cryst. Growth 2006, 295 (1), 97-101.

(38) Anderson, H. W.; Carberry, J. B.; Staunton, H. F.; Sutradhar, B. C. Crystallization of adipic acid. US 5,471,001, 1995.

(39) Bechtel, S.; Rauls, M.; Van Gelder, R.; Simpson, S. C. Crystallization of amino acids using ultrasonic agitation. US 6,992,216 B2, 2006.

(40) Nanev, C. N.; Penkova, A. Colloids Surfaces A Physicochem. Eng. Asp. 2002, 209 (23), 139-145.

(41) Kim, H. J.; Yeo, S. Do. Chem. Eng. Res. Des. 2015, 97, 68-76.

(42) Park, M. W.; Yeo, S. Do. Chem. Eng. Res. Des. 2012, 90 (12), 2202-2208.

(43) Kadam, S. S.; Kulkarni, S. A.; Coloma Ribera, R.; Stankiewicz, A. I.; ter Horst, J. H.; Kramer, H. J. M. Chem. Eng. Sci. 2012, 72 (July 2016), 10-19.

(44) Luque de Castro, M. D.; Priego-Capote, F. Ultrason. Sonochem. 2007, 14 (6), $717-$ 724.

(45) Devarakonda, S.; Evans, J. M. B.; Myerson, A. S. Cryst. Growth Des. 2004, 4 (4), 687690.

(46) Liszka, B. M.; Wagterveld, R. M.; Witkamp, G.-J.; Otto, C. Cryst. Growth Des. 2016, 16 (9), 4839-4845.

(47) Gogate, P. R.; Mujumdar, S.; Pandit, A. B. J. Chem. Technol. Biotechnol. 2003, 78 (April 2002), 685-693.

(48) Li, J.; Bao, Y.; Wang, J. Chem. Eng. Technol. 2013, 36 (8), 1341-1346.

(49) Sayan, P.; Sargut, S. T.; Kiran, B. Ultrason. Sonochem. 2011, 18 (3), 795-800.

(50) Jiang, M.; Papageorgiou, C. D.; Waetzig, J.; Hardy, A.; Langston, M.; Braatz, R. D. Cryst. Growth Des. 2015, 15 (5), 2486-2492.

(51) Mullin, J. W. Crystallization; Butterworth-Heinemann: Oxford, 2001.

(52) Louhi-Kultanen, M.; Karjalainen, M.; Rantanen, J.; Huhtanen, M.; Kallas, J. Int. J. Pharm. 2006, 320 (1-2), 23-29.

(53) Yashima, S.; Kanda, Y.; Sano, S. Powder Technol. 1987, 51 (3), 277-282.

(54) Bari, A. H.; Chawla, A.; Pandit, A. B. Ultrason. Sonochem. 2016.

(55) Gogate, P. R.; Sutkar, V. S.; Pandit, A. B. Chem. Eng. J. 2011, 166 (3), 1066-1082.

(56) Wu, T. Y.; Guo, N.; Teh, C. Y.; Hay, J. X. W. In Advances in Ultrasound Technology for Environmental Remediation; 2013; pp 109-120.

(57) Sutkar, V. S.; Gogate, P. R. Chem. Eng. J. 2009, 155 (1-2), 26-36.

(58) Cintas, P.; Mantegna, S.; Gaudino, E. C.; Cravotto, G. Ultrason. Sonochem. 2010, 17 (6), 985-989.

(59) Gondrexon, N.; Renaudin, V.; Petrier, C.; Boldo, P.; Bernis, A.; Gonthier, Y. Ultrason. Sonochem. 1999, 5 (4), 125-131.

(60) Loranger, E.; Paquin, M.; Daneault, C.; Chabot, B. Chem. Eng. J. 2011, 178, 359-365.

(61) Mason, T. J. Ultrason. Sonochem. 2000, 7 (4), 145-149.

(62) Kaur Bhangu, S.; Ashokkumar, M.; Lee, J. Cryst. Growth Des. 2016, 16 (4), 1934 1941.

(63) Sudha, C.; Srinivasan, K. J. Cryst. Growth 2014, 401, 248-251.

(64) Sander, J. R. G.; Zeiger, B. W.; Suslick, K. S. Ultrason. Sonochem. 2014, 21 (6), 1908-1915.

(65) Wagterveld, R. M.; Boels, L.; Mayer, M. J.; Witkamp, G. J. Ultrason. Sonochem. 2011, 18 (1), 216-225.

(66) Boels, L.; Wagterveld, R. M.; Mayer, M. J.; Witkamp, G. J. J. Cryst. Growth 2010, 312 
(7), 961-966.

(67) Davies, L. A.; Dargue, A.; Dean, J. R.; Deary, M. E. Ultrason. Sonochem. 2015, 23, 424-431.

(68) Nishida, I. Ultrason. Sonochem. 2004, 11 (6), 423-428.

(69) Byrne, T.; Dahal, P. M. Transition metal compound particles and methods of production. US 2013/0272949 A1, 2013.

(70) Pohl, B.; Jamshidi, R.; Brenner, G.; Peuker, U. A. Chem. Eng. Sci. 2012, 69 (1), 365372.

(71) Kaully, T.; Keren, B.; Kimmel, T.; Dekel, O. Method and apparatus for shaping particles by ultrasonic cavitation. US 6,669,122 B2, 2003.

(72) Jordens, J.; Appermont, T.; Gielen, B.; Van Gerven, T.; Braeken, L. Cryst. Growth Des. 2016. 
Figure captions:

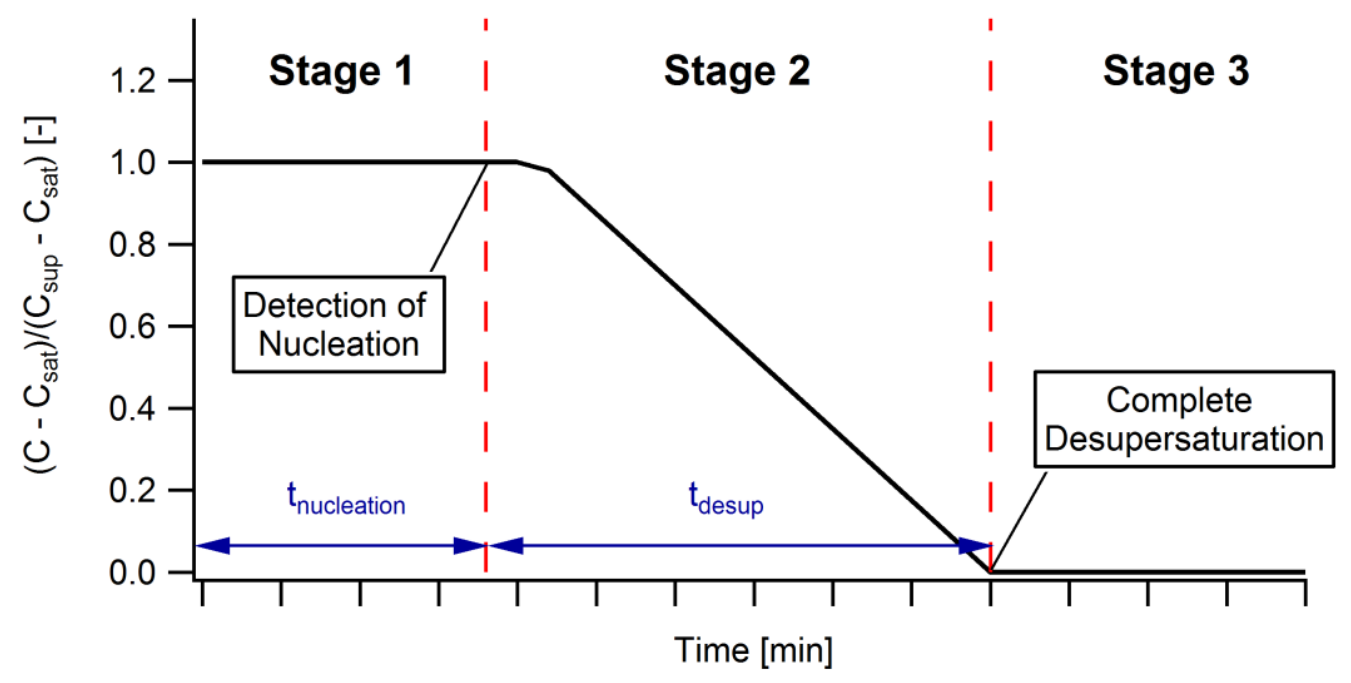

Figure 1: Schematic overview of the progress of the normalized supersaturation level during crystallization and the demarcation of the three stages in which ultrasound is applied. $C$ is the concentration in the solution, $C_{s a t}$ is the solubility level and $C_{s u p}$ is the initial concentration before nucleation.

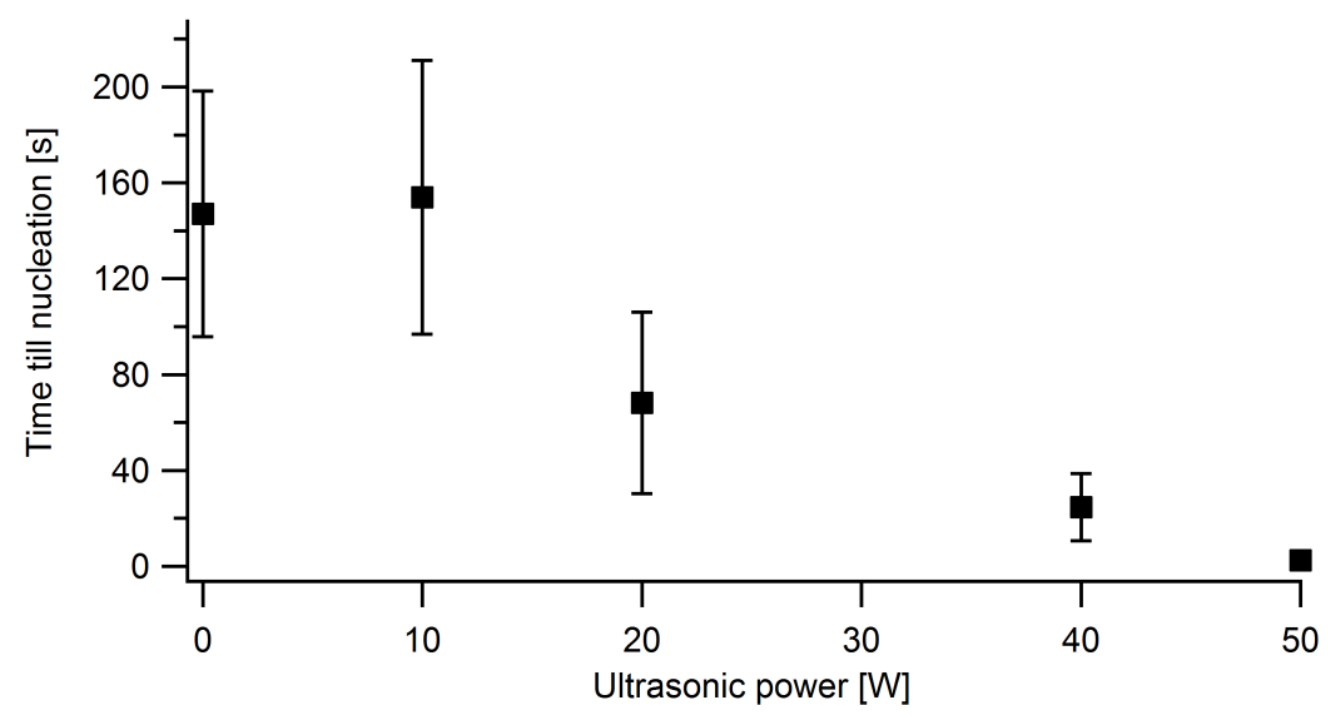

Figure 2: Effect of ultrasonic power on the time till detection of the first nuclei. Isothermal crystallization experiments at $27{ }^{\circ} \mathrm{C}$ using an initial supersaturation of 1.19 were used to obtain these data. Measurements are performed in the recirculation setup at least 5 times with the average and standard deviation being displayed. 


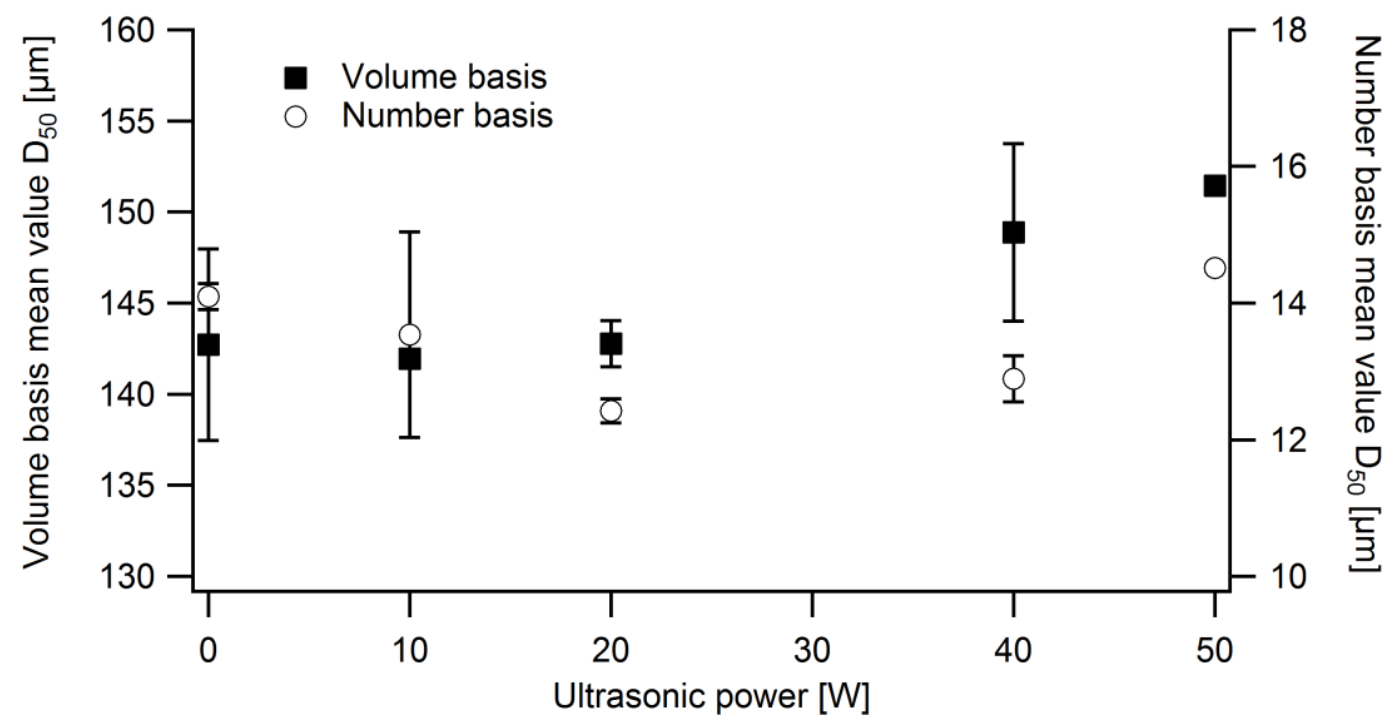

Figure 3: Effect of ultrasonic power during stage 1 on the median particle size $D_{50}$ (volume and number basis) after isothermal crystallization at $27^{\circ} \mathrm{C}$ in the recirculation setup. All experiments were performed twice and the average distribution of both tests is being displayed.

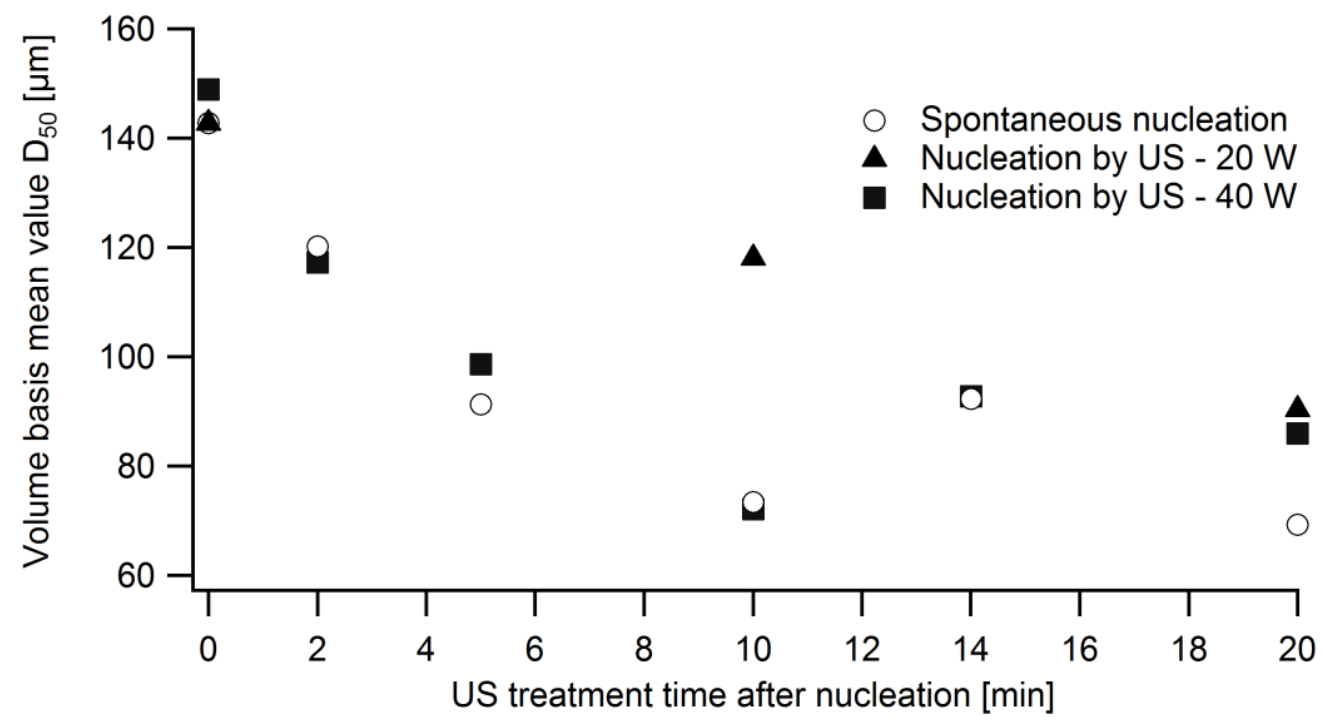

Figure 4: Effect of ultrasonic treatment time in the second stage (after spontaneous or ultrasound-induced nucleation) on the volume basis median particle size $D_{50}$. The crystallization was performed at $27{ }^{\circ} \mathrm{C}$ in the recirculation setup. 

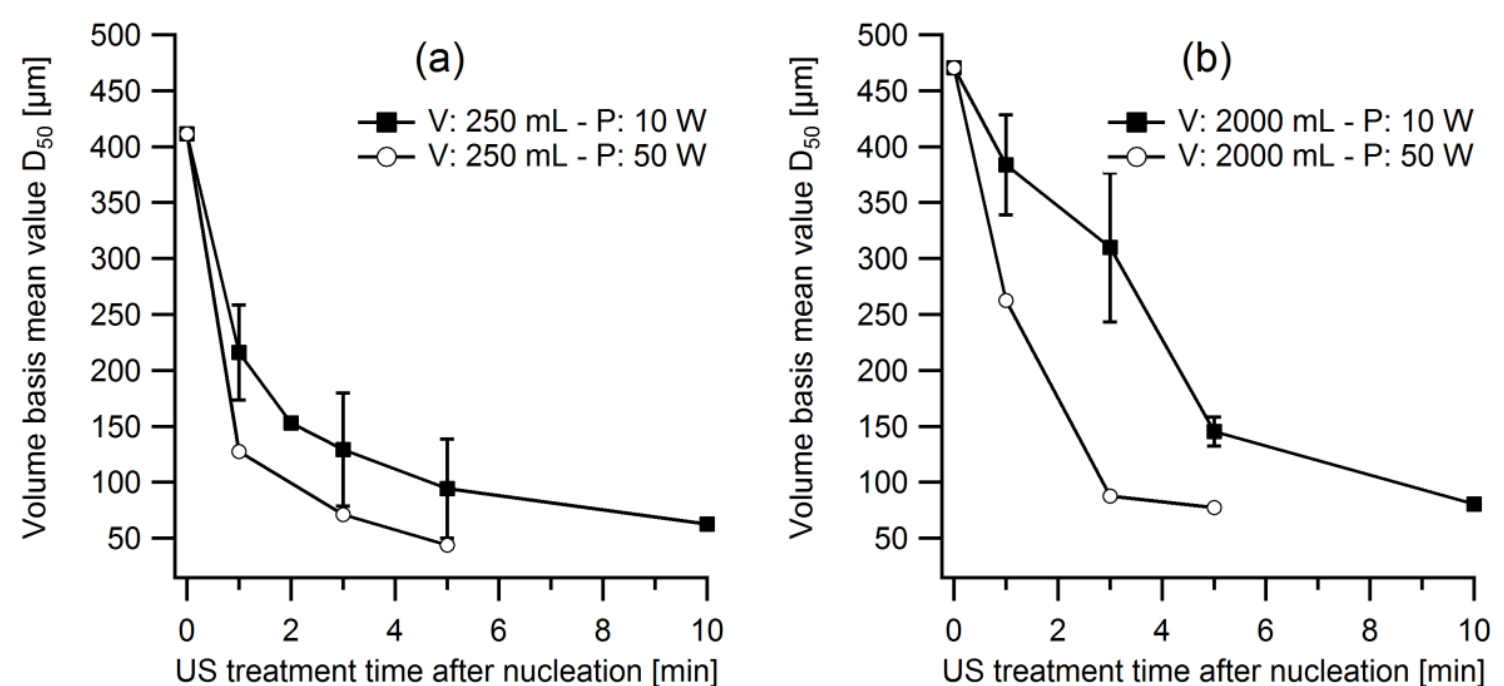

Figure 5: Effect of ultrasonic treatment time and power in stage 2 (after nucleation by ultrasound) on the volume basis median particle size $D_{50}$ after isothermal crystallization at $25{ }^{\circ} \mathrm{C}$ in the batch reactor. Data points including error bars that show the standard deviation were performed twice, while others were only tested once. (a) Slurry volume of $250 \mathrm{~mL}$, (b) Slurry volume of $2000 \mathrm{~mL}$.
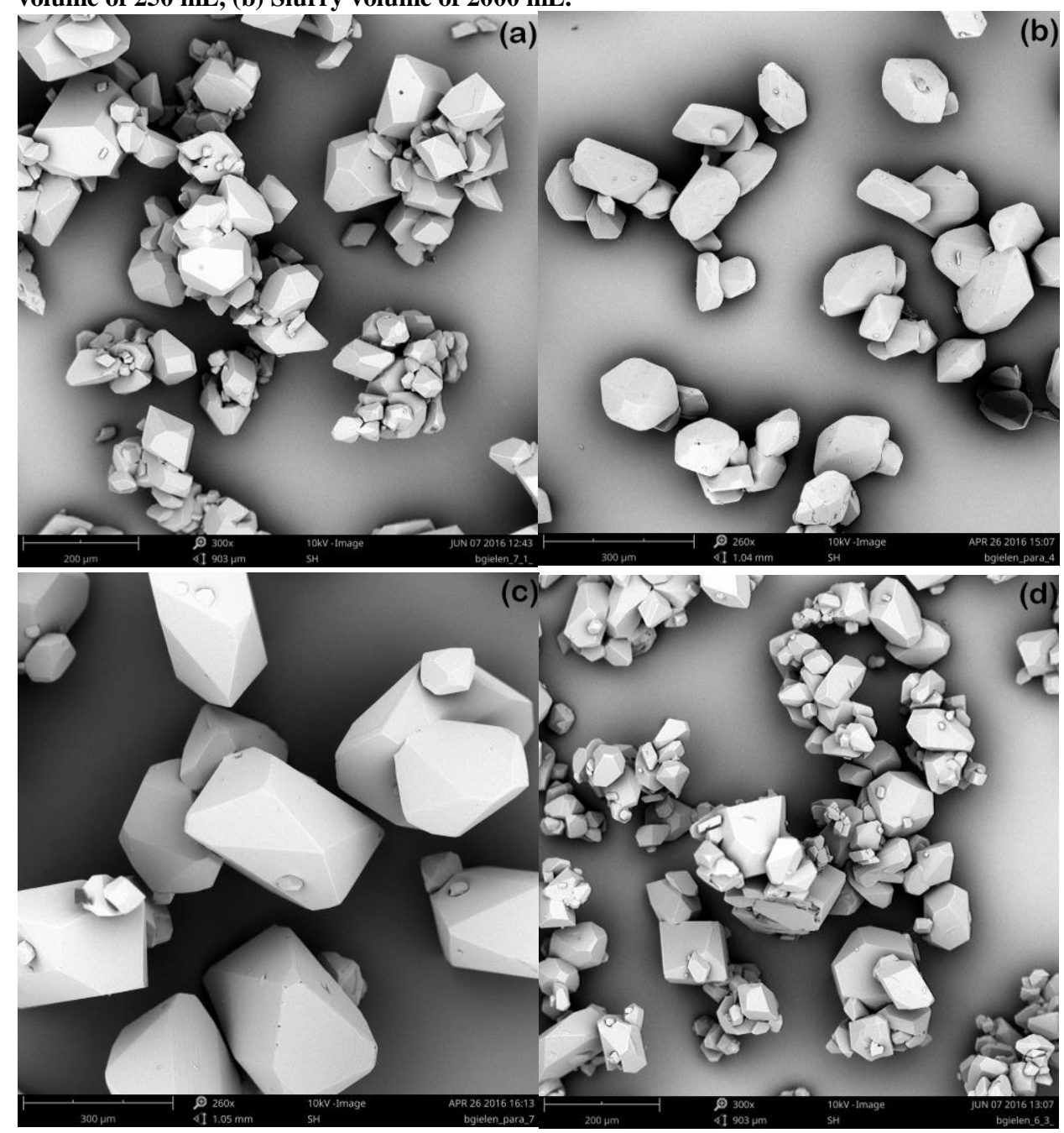


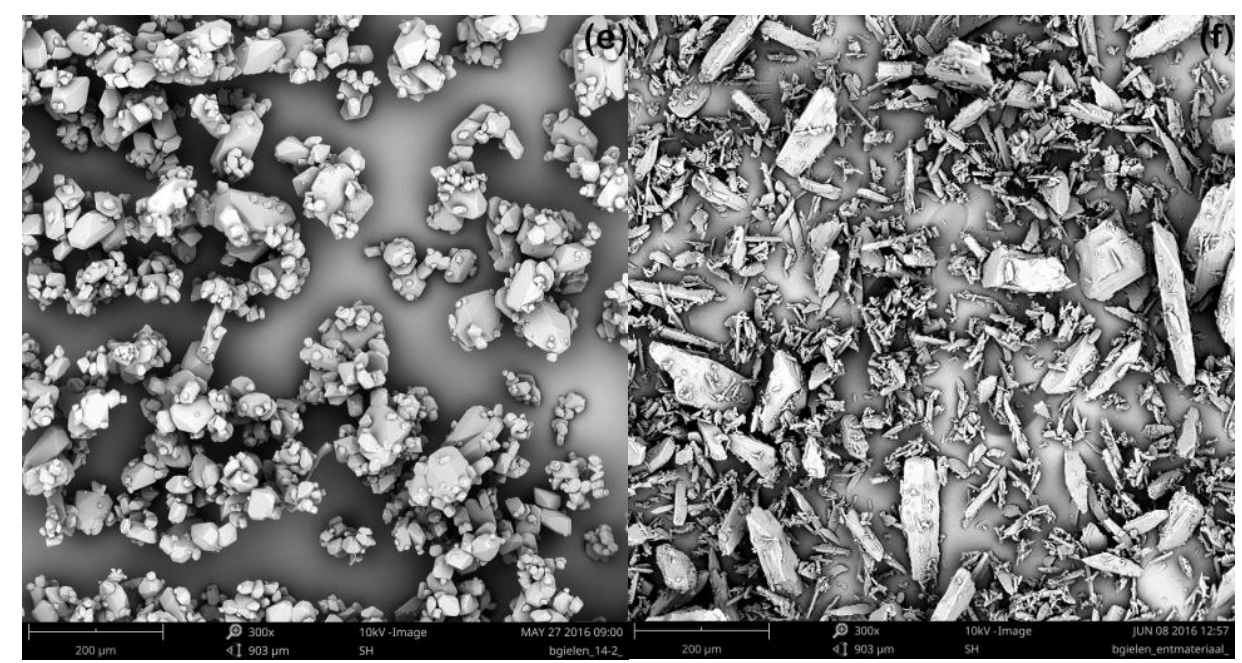

Figure 6: SEM images of paracetamol crystals obtained after isothermal crystallization in the batch and recirculation setup. (a) Batch setup seeded with $1 \mathrm{~m} \%$ seeds (b) Slurry volume of $250 \mathrm{~mL}$ (Batch), seeded with $10 \mathrm{~W}$ ultrasound and 1 min sonication after nucleation, (c) Slurry volume of $2000 \mathrm{~mL}$ (Batch) seeded with $10 \mathrm{~W}$ ultrasound and 1 min sonication after nucleation, (d) Recirculation setup seeded with $1 \mathrm{~m} \%$ seeds, (e) Recirculation setup seeded with $10 \mathrm{~W}$ ultrasound and 1 min sonication after nucleation, (f) Seed material.
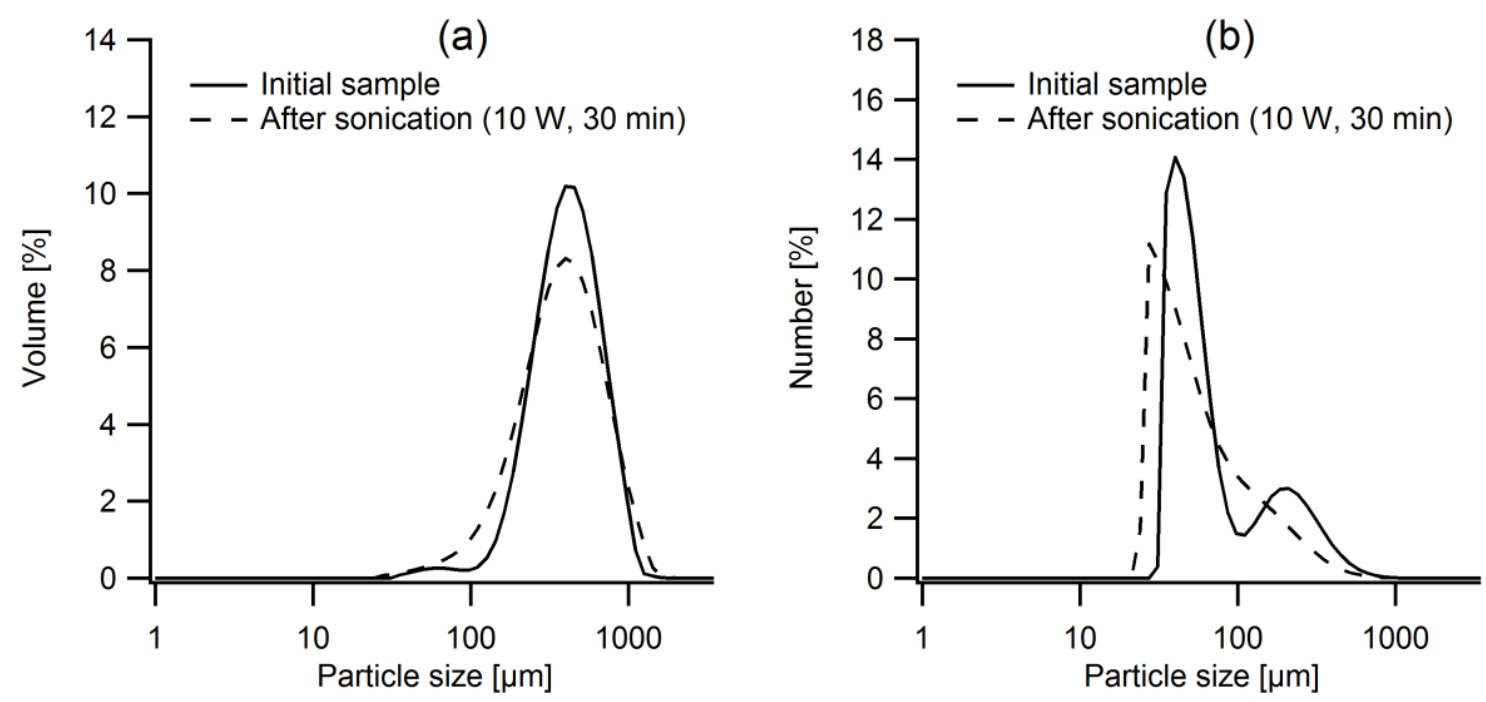

Figure 7: Effect of after-treatment with ultrasound ( $30 \mathrm{~min}, 10 \mathrm{~W}$ ) on the final crystal size distribution in the batch setup. (a) Volume based PSD, (b) Number based PSD. 


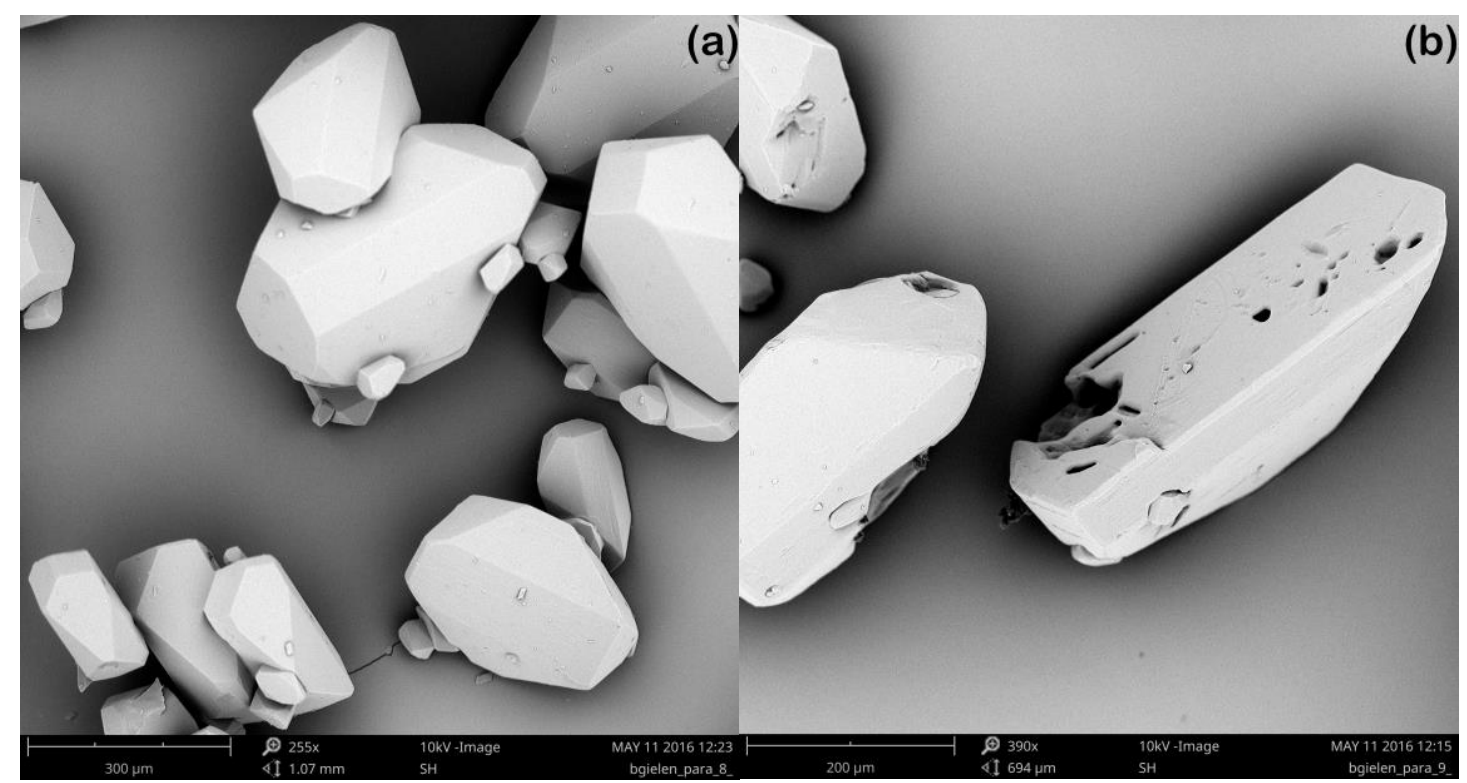

Figure 8: Effect of after-treatment with ultrasound on the crystal morphology, analysed by scanning electron microscopy. (a) Crystals of initial non-sonicated sample, (b) Crystals after sonication with $10 \mathrm{~W}$ for $30 \mathrm{~min}$. 


\section{Supporting Information \\ Particle size control during ultrasonic cooling crystallization of paracetamol}

Bjorn Gielen $^{\dagger+}$, Thomas Claes ${ }^{\dagger}$, Jonas Janssens ${ }^{\ddagger}$, Jeroen Jordens ${ }^{\dagger \dagger}$, Leen C.J. Thomassen ${ }^{\dagger \dagger}$, Tom Van Gerven ${ }^{\dagger}$, Leen Braeken ${ }^{\dagger * *}$

${ }^{\dagger}$ KU Leuven, Department of Chemical Engineering, Celestijnenlaan 200 F, box 2424, 3001 Leuven, BELGIUM

${ }^{\ddagger}$ KU Leuven, Faculty of Engineering Science, Lab4U, Agoralaan building B box 8, 3590 Diepenbeek, BELGIUM

*corresponding author: leen.braeken@kuleuven.be

\section{Content}

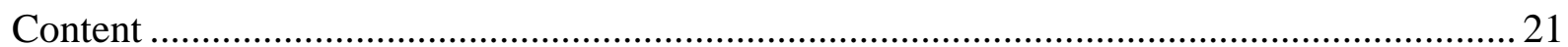

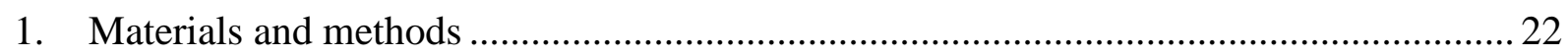

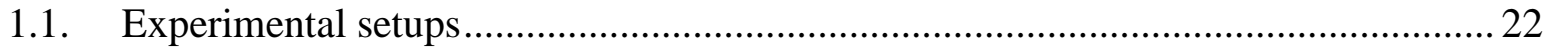

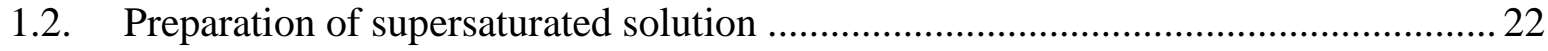

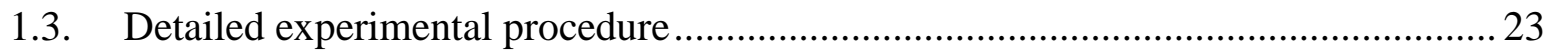

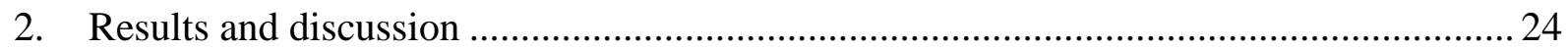

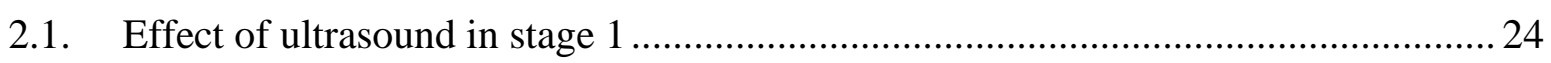

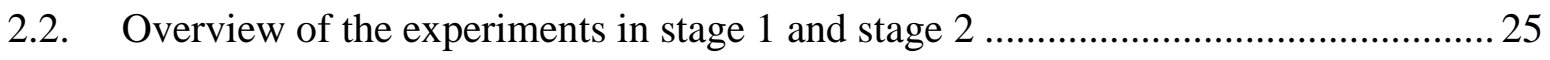

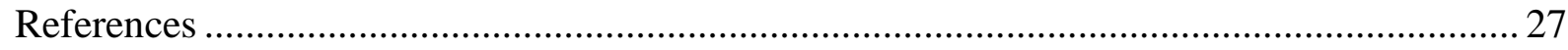




\section{Materials and methods}

\section{Experimental setups}

Figure S9 shows the experimental crystallization setups that were used in this study. The batch setup (a) consisted of a 300 or $2200 \mathrm{~mL}$ jacketed cylindrical tank equipped with an overhead impeller (IKA Labortechnik RW20.N) that operated at a stirring rate of $400 \mathrm{rpm}$. In the recirculation setup (b), a similar jacketed tank of $600 \mathrm{~mL}$ was used in combination with a $5 \mathrm{~mL}$ flow through cell that contained the ultrasonic actuator. A peristaltic pump (Watson Marlow $302 \mathrm{~S}$ ) was used in this case to circulate the solution at $160 \mathrm{~mL} \cdot \mathrm{min}^{-1}$. Temperature control inside both setups was provided by an external thermostatic bath (Lauda Ecosilver RE450) that was connected to a temperature probe submerged in the tank. Ultrasound was supplied by a $30 \mathrm{kHz}$ Hielscher UP50H probe, operated in continuous mode with an adjustable power between $10-50 \mathrm{~W}$.
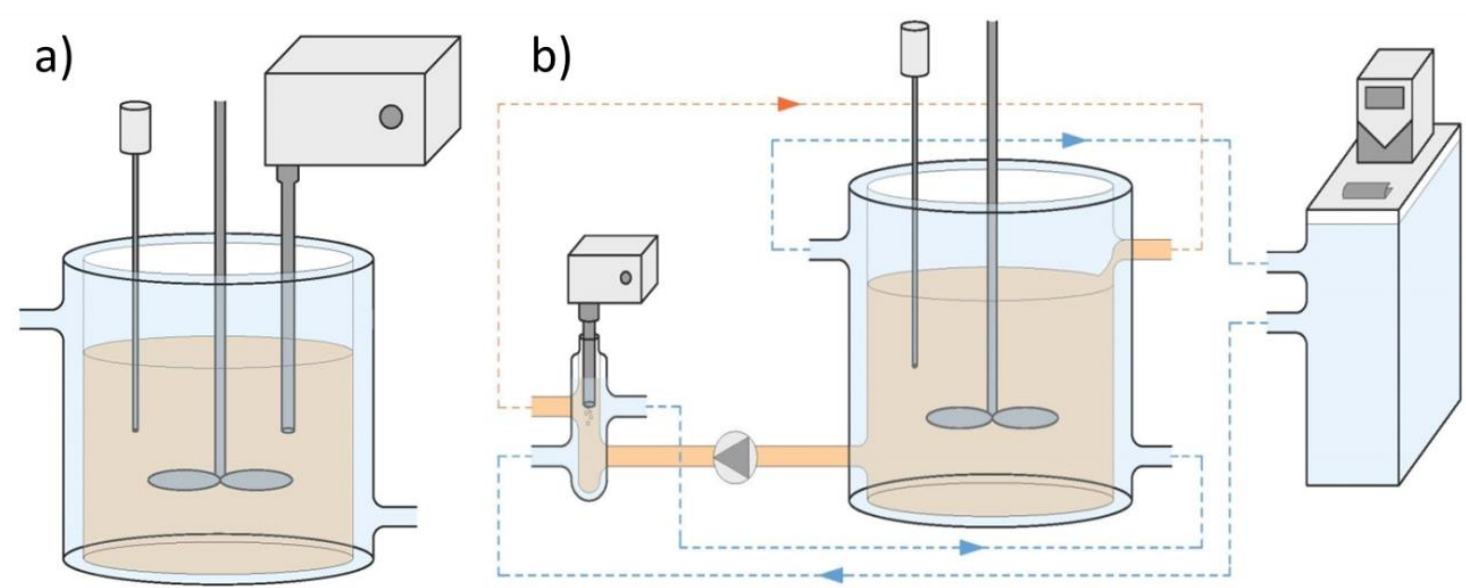

Figure S9: Schematic overview of the experimental setups: a) Jacketed batch setup of $300 \mathrm{~mL}$ or $2200 \mathrm{~mL}$ with overhead stirrer and submerged ultrasonic probe. b) Recirculation setup of $600 \mathrm{~mL}$ with the ultrasonic probe placed in an external $5 \mathrm{~mL}$ flow cell.

\section{Preparation of supersaturated solution}

A 20 g. $\mathrm{kg}^{-1}$ paracetamol solution (Acros Organics, 98\%) was prepared in water (Milli-Q, resistance $18.2 \mathrm{M} \Omega . \mathrm{cm}$ ), provided by a Sartorius-Stedim Arium 611 DI water purification system. To guarantee complete dissolution of the solute the solution was heated to $80{ }^{\circ} \mathrm{C}$, about $46{ }^{\circ} \mathrm{C}$ above the saturation temperature, under continuous stirring. Subsequently, it was filtered over a $0.45 \mu \mathrm{m}$ Millipore HAWP filter to remove any undissolved organic impurities or dust particles. After dilution to a volume of 250,500 or $2000 \mathrm{~mL}$, the solution was transferred into a batch or recirculation crystallizer. This operation caused the temperature to drop to $50 \pm 5{ }^{\circ} \mathrm{C}$, far above the solubility temperature where spontaneous nucleation can occur. ${ }^{1,2}$ Next, the solution was cooled at a linear cooling rate of $0.5^{\circ} \mathrm{C} . \mathrm{min}^{-1}$ in the setup till a constant temperature in order to obtain a solution with a fixed supersaturation. In the experiments involving the recirculation setup, $15 \mathrm{~mL}$ of methanol (VWR Chemicals, UHPLC grade) was added as soon as the temperature reached $45^{\circ} \mathrm{C}$ during cooling. This action prevented any paracetamol crystals to stick to the walls of the flow cell in the recirculation loop which would affect the final crystal properties. As addition of methanol can influence the solubility of paracetamol, an experimental solubility curve was made which allowed to 
determine the final supersaturation level that was maintained during the experiments. These data points are obtained experimentally by determination of the clear point during slow heating $\left(<0.1{ }^{\circ} \mathrm{C} \cdot \mathrm{min}^{-1}\right)$ after addition of a fixed amount of paracetamol to an aqueous solution containing $2.3 \mathrm{~m} \%$ methanol. The temperature at which complete dissolution occurred was assessed by a combination of visual detection and FBRM measurements. Figure S10 shows this solubility data along with the solubility of paracetamol in pure water which was obtained from literature. ${ }^{1}$ This plot indicates that the difference in solubility by addition of methanol is only marginal in the studied concentration and temperature range. In the tests with the batch configuration, no methanol was added to the solution.

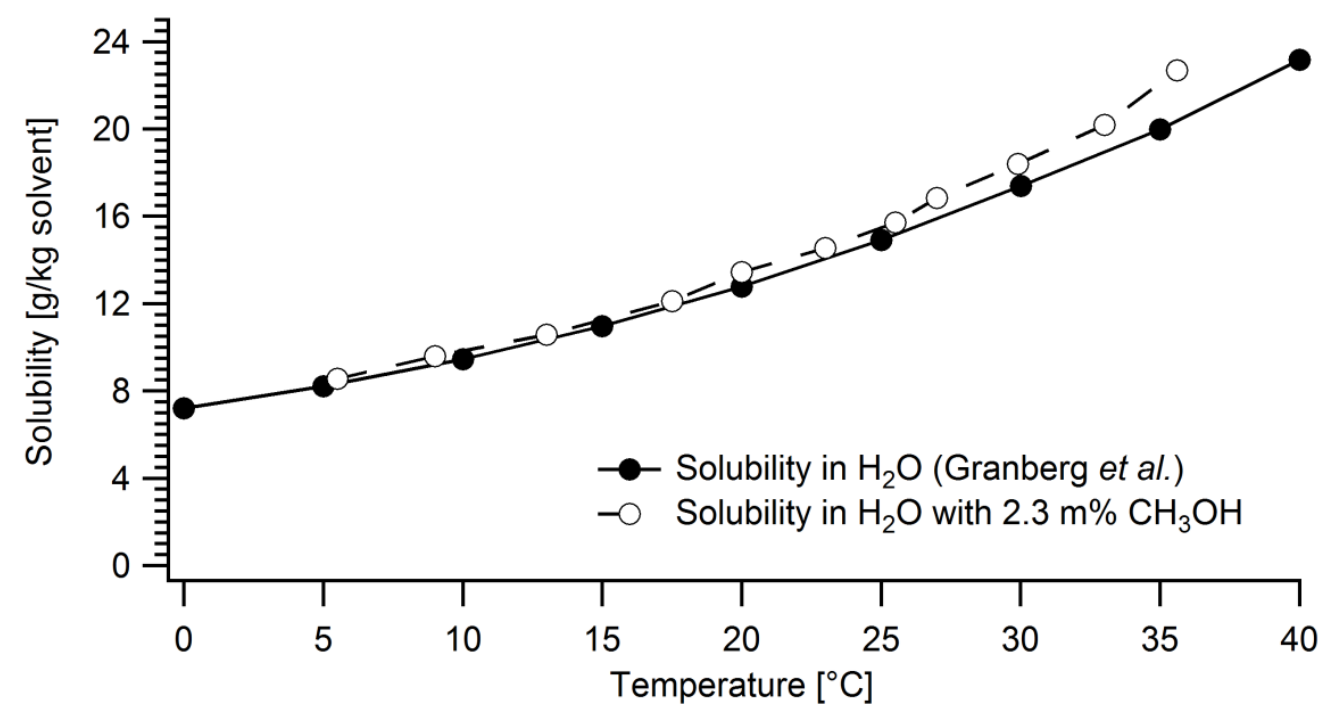

Figure S10: Solubility plot of paracetamol in pure water (based on Granberg et al. ${ }^{1}$ ) and in a $2.3 \mathrm{~m} \%$ methanol/water mixture.

\section{Detailed experimental procedure}

In all experiments, the supersaturated solution was maintained at a fixed temperature throughout the entire process. In the recirculation setup, crystallization was performed at $27{ }^{\circ} \mathrm{C}$, while a temperature of $25^{\circ} \mathrm{C}$ was maintained in the batch configuration. This corresponds to a supersaturation ratio of 1.19 and 1.35 , respectively. These conditions were chosen in order to generate a supersaturated solution in which spontaneous nucleation did not occur immediately as soon as the target temperature was obtained. Since spontaneous nucleation could occur more easily in the recirculation setup due to additional shear forces of the pump, a lower initial supersaturation level was used in comparison to the batch reactor.

Starting from the supersaturated solution with a concentration $C_{\text {sup }}\left(20 \mathrm{~g}^{\mathrm{kg}} \mathrm{kg}^{-1}\right)$ in both setups, the concentration $C$ declines after a certain lag time following the detection of the first crystals in the solution. The actual nucleation usually occurs before the first observation of crystals in the solution since a certain time is needed to grow the crystals to a detectable size. ${ }^{3,4}$ In this work nucleation is detected by visual observation. Although several other methods such as FBRM, FTIR, light scattering, etc. are exploited in literature, it is emphasized that this simple technique allows for early detection of nucleation in a reproducible way, once these have grown to a detectable size. ${ }^{2-5}$ After complete 
desupersaturation at constant temperature, the solubility level $C_{\text {sat }}$ is obtained. The slurry, obtained after this isothermal desupersaturation, was then filtered over a $0.45 \mu \mathrm{m}$ Millipore HAWP filter to isolate the crystals from the saturated mother liquor. All crystals obtained after filtration, were dried in an oven at $40{ }^{\circ} \mathrm{C}$ until the weight of the sample was constant. Next, the crystal size distribution of the sample was determined by offline measurements in $n$ hexane with addition of about $1 \mathrm{~m} \%$ lecithin, using a Malvern Mastersizer 3000 laser diffraction analyser with a Hydro EV dispersion unit. Lecithin (Acros organics, > 98\% pure) was added in order to prevent adhesion of paracetamol crystals to the glass walls of the measurement cell. Additionally, a combination of a high stirring rate of $2400 \mathrm{rpm}$ and a single sonication burst of 10 seconds in the Hydro EV unit guaranteed proper dispersion of any aggregated particles that might have formed during drying. Apart from size measurements, the crystal shape was visualized using a Phenom Pro scanning electron microscope (SEM). Prior to imaging, the samples were coated with gold for 2 min using a constant current of 30 $\mathrm{mA}$.

\section{Results and discussion}

\section{Effect of ultrasound in stage 1}

In these tests, ultrasound is only enabled to induce nucleation in a supersaturated solution. Afterwards, the crystals are grown in silent conditions till the supersaturation is depleted. The complete volume based particle size distribution plots obtained during these experiments are displayed in Figure S11. This analysis shows that a unimodal distribution with a comparable span and particle size is obtained under silent and sonicated conditions.

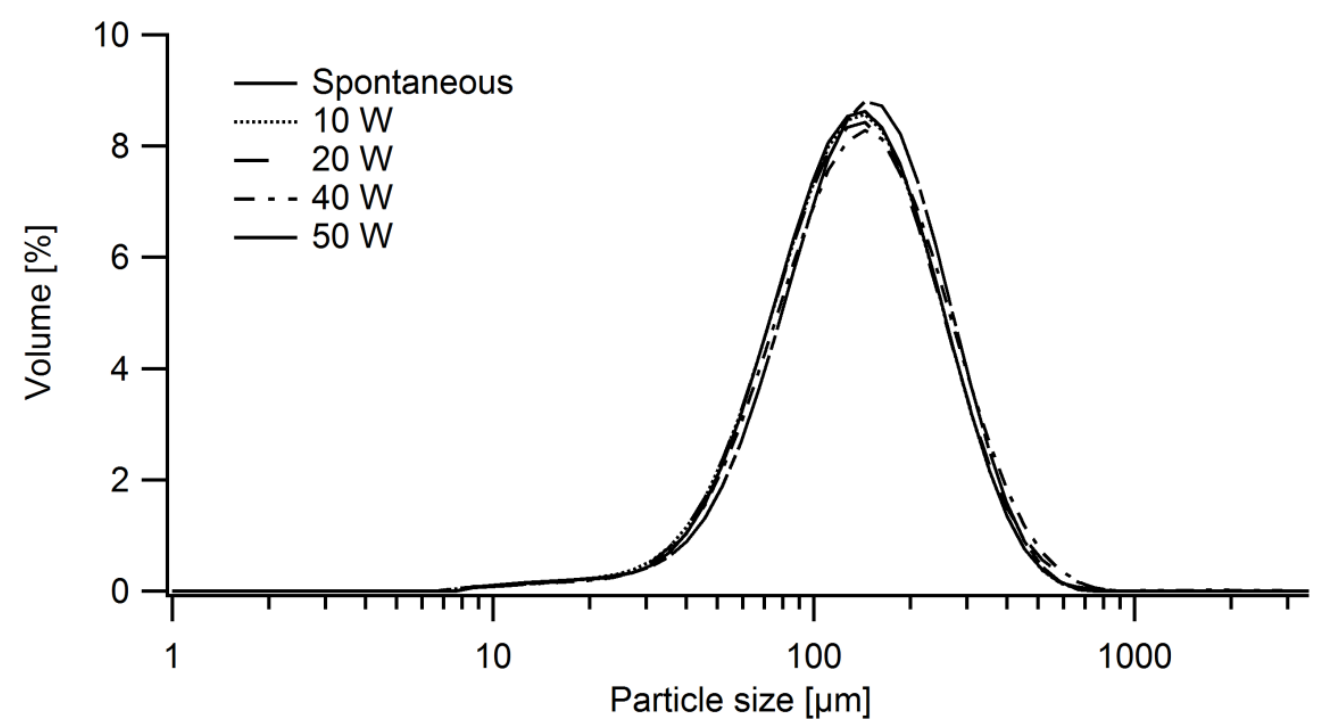

Figure S11: Effect of ultrasonic power on the final crystal size distribution. In the ultrasound assisted tests, sonication was enabled till the detection of the first nuclei, followed by 2 hours stirring in the absence of ultrasound at constant temperature $\left(27^{\circ} \mathrm{C}\right)$. Spontaneous crystallization $\left(\begin{array}{ll}0 & \mathrm{~W}\end{array}\right)$ was performed without exposure to ultrasound. All experiments were performed twice and the average distribution of both tests is being displayed. 
Overview of the experiments in stage 1 and stage 2

Table S1 provides an overview of the settings and the results of the experiments in which ultrasound was applied in stage 1 or stage 2. Table S2: Overview of the experiments with application of ultrasound in stage 1 and stage 2

\begin{tabular}{|c|c|c|c|c|c|c|c|c|}
\hline & Stage & Reactor & \# exp. & $\begin{array}{c}\text { Ultrasonic } \\
\text { Power }\end{array}$ & $\begin{array}{c}\text { Ultrasonic } \\
\text { Exposure time }\end{array}$ & $\begin{array}{c}\text { Time } \\
\text { till nucleation }\end{array}$ & \multicolumn{2}{|c|}{$\mathbf{D}_{\mathbf{x}, \mathbf{5 0}}$} \\
\hline & & & & & & & Volume Based & Number based \\
\hline \multirow{5}{*}{$\begin{array}{l}\text { Effect of various US } \\
\text { power on time till } \\
\text { nucleation }\end{array}$} & 1 & Recirc. & 5 & 0 & - & $147 \pm 51$ & $142.7 \pm 5.3$ & $14.1 \pm 0.19$ \\
\hline & 1 & Recirc. & 5 & 10 & - & $154 \pm 57$ & $141.9 \pm 0.39$ & $13.5 \pm 1.5$ \\
\hline & 1 & Recirc. & 6 & 20 & - & $68.3 \pm 38$ & $142.8 \pm 1.3$ & $12.4 \pm 0.17$ \\
\hline & 1 & Recirc. & 5 & 40 & - & $24.6 \pm 14$ & $148.9 \pm 4.9$ & $12.9 \pm 0.34$ \\
\hline & 1 & Recirc. & 5 & 50 & - & $2.60 \pm 1.5$ & $151.4 \pm 0.47$ & $14.5 \pm 0.035$ \\
\hline \multirow{9}{*}{$\begin{array}{c}\text { Effect of additional } \\
\text { exposure to ultrasound } \\
\text { after ultrasound-induced } \\
\text { nucleation }\end{array}$} & 2 & Recirc. & 1 & 40 & 0 & $24.6 \pm 14$ & 148.9 & - \\
\hline & 2 & Recirc. & 1 & 40 & 2 & $24.6 \pm 14$ & 117.2 & - \\
\hline & 2 & Recirc. & 1 & 40 & 4 & $24.6 \pm 14$ & 98.7 & - \\
\hline & 2 & Recirc. & 1 & 40 & 10 & $24.6 \pm 14$ & 72.1 & - \\
\hline & 2 & Recirc. & 1 & 40 & 14 & $24.6 \pm 14$ & 92.7 & - \\
\hline & 2 & Recirc. & 1 & 40 & 20 & $24.6 \pm 14$ & 86.0 & - \\
\hline & 2 & Recirc. & 1 & 20 & 0 & $68.3 \pm 38$ & 142.7 & - \\
\hline & 2 & Recirc. & 1 & 20 & 10 & $68.3 \pm 38$ & 118.1 & - \\
\hline & 2 & Recirc. & 1 & 20 & 20 & $68.3 \pm 38$ & 90.4 & - \\
\hline \multirow{6}{*}{$\begin{array}{l}\text { Effect of additional } \\
\text { exposure to ultrasound } \\
\text { after spontaneous } \\
\text { nucleation }\end{array}$} & 2 & Recirc. & 1 & 40 & 0 & $147 \pm 51$ & 142.7 & - \\
\hline & 2 & Recirc. & 1 & 40 & 2 & $147 \pm 51$ & 120.2 & - \\
\hline & 2 & Recirc. & 1 & 40 & 4 & $147 \pm 51$ & 91.2 & - \\
\hline & 2 & Recirc. & 1 & 40 & 10 & $147 \pm 51$ & 73.4 & - \\
\hline & 2 & Recirc. & 1 & 40 & 14 & $147 \pm 51$ & 92.3 & - \\
\hline & 2 & Recirc. & 1 & 40 & 20 & $147 \pm 51$ & 69.3 & - \\
\hline
\end{tabular}




\begin{tabular}{|c|c|c|c|c|c|c|c|c|}
\hline & Stage & Reactor & \# exp. & $\begin{array}{c}\text { Ultrasonic } \\
\text { Power }\end{array}$ & $\begin{array}{c}\text { Ultrasonic } \\
\text { Exposure time }\end{array}$ & $\begin{array}{c}\text { Time } \\
\text { till nucleation }\end{array}$ & \multicolumn{2}{|c|}{$\mathbf{D}_{\mathbf{x}, \mathbf{5 0}}$} \\
\hline & & & & & & & Volume Based & Number based \\
\hline \multirow{10}{*}{$\begin{array}{c}\text { Effect of additional } \\
\text { exposure to ultrasound } \\
\text { after ultrasound-induced } \\
\text { nucleation }\end{array}$} & 2 & Batch $250 \mathrm{~mL}$ & 1 & 10 & 0 & - & 411.3 & - \\
\hline & 2 & Batch $250 \mathrm{~mL}$ & 2 & 10 & 1 & - & $216.0 \pm 42$ & - \\
\hline & 2 & Batch $250 \mathrm{~mL}$ & 1 & 10 & 2 & - & 152.7 & - \\
\hline & 2 & Batch $250 \mathrm{~mL}$ & 2 & 10 & 3 & - & $129.4 \pm 51$ & - \\
\hline & 2 & Batch $250 \mathrm{~mL}$ & 2 & 10 & 5 & - & $94.3 \pm 44$ & - \\
\hline & 2 & Batch $250 \mathrm{~mL}$ & 1 & 10 & 10 & - & 62.5 & - \\
\hline & 2 & Batch $250 \mathrm{~mL}$ & 1 & 50 & 0 & - & 411.3 & - \\
\hline & 2 & Batch $250 \mathrm{~mL}$ & 1 & 50 & 1 & - & 127.4 & - \\
\hline & 2 & Batch $250 \mathrm{~mL}$ & 1 & 50 & 3 & - & 70.9 & - \\
\hline & 2 & Batch $250 \mathrm{~mL}$ & 1 & 50 & 5 & - & 43.8 & - \\
\hline \multirow{9}{*}{$\begin{array}{c}\text { Effect of additional } \\
\text { exposure to ultrasound } \\
\text { after ultrasound-induced } \\
\text { nucleation }\end{array}$} & 2 & Batch $2000 \mathrm{~mL}$ & 1 & 10 & 0 & - & 470.3 & - \\
\hline & 2 & Batch $2000 \mathrm{~mL}$ & 2 & 10 & 1 & - & $383.5 \pm 45$ & - \\
\hline & 2 & Batch $2000 \mathrm{~mL}$ & 2 & 10 & 3 & - & $310.1 \pm 67$ & - \\
\hline & 2 & Batch $2000 \mathrm{~mL}$ & 2 & 10 & 5 & - & $145.2 \pm 13$ & - \\
\hline & 2 & Batch $2000 \mathrm{~mL}$ & 1 & 10 & 10 & - & 80.5 & - \\
\hline & 2 & Batch $2000 \mathrm{~mL}$ & 1 & 50 & 0 & - & 470.3 & - \\
\hline & 2 & Batch $2000 \mathrm{~mL}$ & 2 & 50 & 1 & - & 262.4 & - \\
\hline & 2 & Batch $2000 \mathrm{~mL}$ & 2 & 50 & 3 & - & 87.7 & - \\
\hline & 2 & Batch $2000 \mathrm{~mL}$ & 2 & 50 & 5 & - & 77.2 & - \\
\hline
\end{tabular}




\section{References}

(1) Granberg, R. a.; Rasmuson, Å. C. J. Chem. Eng. Data 1999, 44 (6), 1391-1395.

(2) Fujiwara, M.; Chow, P. S.; Ma, D. L.; Braatz, R. D. Cryst. Growth Des. 2002, 2 (5), 363-370.

(3) Liszka, B. M.; Wagterveld, R. M.; Witkamp, G.-J.; Otto, C. Cryst. Growth Des. 2016, 16 (9), 4839-4845.

(4) Kadam, S. S.; Kulkarni, S. A.; Coloma Ribera, R.; Stankiewicz, A. I.; ter Horst, J. H.; Kramer, H. J. M. Chem. Eng. Sci. 2012, 72 (July 2016), 10-19.

(5) Kulkarni, S. A.; Kadam, S. S.; Meekes, H.; Stankiewicz, A. I.; Ter Horst, J. H. Cryst. Growth Des. 2013, 13 (6), 2435-2440. 